\title{
Guiding Teaching Strategies with the Education Platform during the COVID-19 Epidemic: Taking Guiyang No.1 Middle School Teaching Practice as an Example
}

\author{
Nan Zhao, ${ }^{1}$ Xinyi Zhou, ${ }^{2}$ Bo Liu, ${ }^{1}$ Wei Liu ${ }^{3}$
}

1. Guiyang No.1 Middle School, Guiyang 550000, Guizhou, China

2. Chengdu Teachers College, Chengdu 610000, China

3. Education Bureau of Nanchong, Nanchong 637000, Sichuan, China

\begin{abstract}
During the COVID-19 epidemic, how to use online education platforms to teach and ensure the effectiveness of home study for students is a topic of concern for many high schools. During the epidemic, Guiyang No.1 Middle School used the information management platform, based on the actual situation of the school, combined multiple resources, and rationally used the online education platform to guide and teach, which effectively guaranteed the implementation of "School's Out, But Class's On” i.e. suspending classes without stopping learning. Based on the practical exploration of Guiyang No.1 Middle School, we explored the strategies of using educational platforms to guide teaching during the epidemic.
\end{abstract}

Sci Insigt Edu Front 2020; 5(2):531-539.

Doi: 10.15354/sief.20.rp005

Keywords: COVID-19 Epidemic; Online Teaching; Online Teaching Platform; Educational Big Data; High School

\footnotetext{
About the Authors: Nan Zhao, Guiyang No.1 Middle School, Guiyang 550000, Guizhou, China. Email:1239838640@qq.com.

Bo Liu, Guiyang No.1 Middle School, Guiyang 550000, Guizhou, China. Email: 1208644137@qq.com.

Wei Liu, Education Bureau of Nanchong, Nanchong 637000, Sichuan, China. Email: niuniu@qq.com.

Correspondence to: Xinyi Zhou, Network and Information Center, Chengdu Normal University, Chengdu 610000, China. Email: neemo@126.com.

Conflict of Interests: None.
} 
$\mathrm{W}$

ITH the rapid development of information technology, the Internet, cloud computing, big data, Internet of Things, artificial intelligence and other technologies have been widely used in education. The multiplication function of the cross integration of information technology and education is having an epoch-making impact on education.

Affected by the COVID-19 epidemic, normal classroom teaching could not be carried out. Schools move teaching from offline to online, and teachers use the Internet to carry out online teaching. How to use the online platform for online teaching, especially the senior high school students who are about to face the college entrance examination is particularly important. How the school can ensure the quality of students' online learning through online teaching; at the same time, how to let students' develop physically and mentally in a comprehensive and healthy way has become a topic of common concern to everyone.

Guiyang No. 1 Middle School in Guiyang City, Guizhou Province serves as a provincial demonstration modern educational technology experimental school. The school gives full play to the existing advantages of the school, and with the help of national and local platforms and resources, it has formed an online teaching model with students as the mainstay, ensuring the quality of online learning for students, and effectively implementing “School's Out, But Class's On”. We herein use the school's specific practice as an example to explore how to use online education platforms to teach during the COVID-19 epidemic to ensure students' home study strategies.

\section{Online Education Related Concepts}

\section{Network Teaching Platform}

The network teaching platform is the migration of the Internet in the field of education (Lv, et al., 2017). It is the infrastructure of future education informatization and the product of technology. It evolves with the development of technology. It includes all the hardware computing resources required for educational informatization. After these resources are virtualized, they can provide a good platform for educational institutions, education practitioners and students. The role of the platform is to provide cloud services for the education field (Zhang \& Tong, 2010), so that learners can learn better.

Therefore, some scholars believe that by using online education platforms, learners can participate in the construction of learning and can progress in exploration and discussion in order to achieve a multi-dimensional and comprehensive grasp of knowledge (Garrison \& Terry, 1998). As long as teachers have a better understanding of students, educators can adapt online courses to learners' needs and maximize their success in online learning environments (Black, et al., 2008).

\section{Educational Big Data}

Educational big data refers to the data collection generated during the entire educational activity process and collected according to educational needs, all of which are used for 
educational development and can create huge potential value. Compared with traditional education data, the collection of educational big data has stronger real-time, coherence, comprehensiveness and naturalness; its analysis and processing are more complex and diverse, and its applications are more diverse and deep (Yang, et al., 2016).

Educational big data, as the soul of intellectualization of education, aggregates and stores information assets in the field of education, and is the most important foundation for the development of intelligent education (Ke, 2013). Some people believe that big data in education will promote important changes in several aspects of education: first, the educational process will change from "non-quantified" to "quantifiable", and behavioral information of teaching and learning will be recorded more and more accurately; Second, from "experienced" to "scientific" in educational decision-making, data-driven decision-making will become more and more reliable. Third, the educational model will change from "popularization" to "personalized". Learning analysis technology will give teachers an understanding of each the ability of a "real student" to teach students according to their aptitude. Fourth, education management goes from "invisible" to "visible", through which more intuitive, accurate, and efficient education resources and business management will occur (Yang, et al., 2016).

\section{The Basics of Schools Using Online Education Plat- forms for Teaching during the Epidemic}

\section{The School's Information Infrastructure is Relatively Com- plete}

With the continuous advancement of national education informatization, schools continue to improve the informatization infrastructure. The school has established a public service platform for education resources and a public service platform for education management, and has continuously updated and optimized the campus platform to meet various needs for safe, flexible, personalized, high-speed, and high-quality information. With the technical support of educational information enterprises, it provides support and services for teaching research and management through modern technologies such as big data analysis, and achieves better integration with education and teaching.

At the same time, the school attaches great importance to the cultivation of the ability of teachers and students to apply information. The practical application of courses, projects, and seminars has promoted the construction of curriculum resources and the improvement of teachers 'and students' educational technology application capabilities.

During the COVID-19 epidemic, the school established an online teaching platform based on the school's teaching and management platform, combined with the national education platform, the education cloud platform of both Guizhou Province and Guiyang City. At the same time, the school's cultivation of the application level of 
teacher-student education informatization provided a basic guarantee for online teaching during the epidemic.

\section{Schools Actively Develop School-Based Online Teaching Re- sources}

In the course of advancing the education informatization infrastructure, the school will fully explore the value of teachers' own curriculum resources in combination with the actual situation of the school. The school strengthens the construction of teaching courseware, teaching design, teaching materials, etc., develops and properly integrates the network teaching resources of the school, and forms a school-based network teaching resource database.

During the epidemic, the National Education Resources Public Service Platform opened a national network cloud classroom. Based on the course resources that won the ministerial award for the "one teacher for one excellent course; one lesson for one excellent teacher" project, it absorbs other high-quality online course teaching resources and provides resource support for schools to carry out online teaching. In addition, under the guidance of the Education Department of Guizhou Province, the Guiyang Education Bureau organized more than 600 outstanding teachers from 12 schools in Guiyang to record a total of more than 1,600 online courses on "Sunshine Campus • Air Guizhou Course", which is aimed at elementary and middle school students in the province.

The school organizes teachers and homeroom teachers of each class to screen the rich online teaching resources provided by the nation, provinces and cities in accordance with their own learning characteristics. Select learning resources that match the student's academic situation and guide the learning content to ensure the effectiveness of online learning.

\section{The School Establishes a Classroom Teaching Model with Students as the Main Body}

With the comprehensive progress of the national curriculum reform, schools have been insisting on the reform of teaching methods. Pay attention to the construction of classroom teaching based on student autonomous learning and group cooperative learning. During the exploration, the school gradually established an education concept aimed at the autonomous development of students. Strengthen the guidance of students' learning methods in classroom teaching. The school advocates autonomous learning, encourages autonomous learning, self-exploration, self-discovery, and self-acquisition of knowledge. Give full play to the potential of students' own development, return the classroom to the students as much as possible, and highlight the student's subjective status. Through the optimization of teaching methods, students' self-learning ability and the spirit of active inquiry had been cultivated, which provides core support for this online teaching. 


\section{Establish a More Mature Home-School Management Mecha- nism}

For a long time, schools attach importance to home-school communication and firmly establish the correct school-family connection concept. Each class has a class QQ group and a WeChat group based on the public communication platform. Each class has formed a mature home-school management mechanism centered on the homeroom teacher and assisted by other teachers.

During the COVID-19 epidemic, each class made full use of WeChat groups, Dingding group, and QQ group, etc., providing students and parents with an effective digital management platform for communication and interaction. Through the platform, teachers can publish learning tasks online in real time and check the completion of student assignments in real time, and provide with counseling and answering questions. Students complete the learning tasks in time through the computer and mobile phones, and realize online learning and submission of homework. Parents use the platform to interact with teachers in a timely manner and maintain communication, forming a good home-school co-education model.

\section{Measures to Use Online Platforms for Teaching dur- ing the COVID-19 Epidemic}

With the help of national and local public education platforms and educational resources, the school has formed an online teaching model based on a strict teaching management system, diversified teaching forms as the core, and multiple evaluation methods as the guarantee.

\section{A Variety of Online Teaching Modes with Live Teaching as the Mainstay}

Teachers use a variety of forms such as public communication platforms (Dingding Group, WeChat Group, QQ Group), as well as cloud classes for corporate education cloud platforms, and Tencent classroom for online teaching. These diverse forms of online teaching complement each other and provide guarantee for the quality assurance of online teaching during the epidemic.

When using "Dingding" for live lessons, teachers can choose online teaching tools such as PowerPoint, Seewo whiteboard, Seewo EN5 according to their own needs and habits. After the live broadcast is completed, the teacher can arrange accurate remedial assignments based on the students' response to the class (message interaction during the live broadcast). Students complete and submit their homework during the evening self-study (19: 00-23: 00), and the relevant class teachers promptly correct and give targeted comments.

\section{Homework Training Based on Big Data Analysis}


It has become the norm in the field of education in China to instruct teachers and students through big data in education. More and more schools are using educational big data analysis platforms to achieve personalized learning for students and targeted teaching by teachers. During the COVID-19 epidemic, the school used multiple platforms to conduct online assignments and online assessments for all students.

After the student's homework or test is completed, upload it to the system platform. Teachers review student assignments and quiz on the platform and the platform automatically collects student assignments or quizzes every day. The system automatically analyzes student work or test data to provide accurate learning reports for each student. For the common problems of the students in the study report, the teacher gave a collective lecture and let the students do common exercises; for the individual problems of different students in the study report, the teacher carried out hierarchical teaching based on the student's study report and the students' cognitive level, and performed stratified training.

What is particularly commendable is that after each practice and assessment, the system will analyze the statistics of the students' practice results. Through the homework analysis, the teacher can get the grades, class common problems and personality errors of the homework each week. Common mistakes refer to most students who will make mistakes in the practice process. Personality mistakes are a few students' mistakes. For common mistakes, the system will automatically push parallel exercises, and the teacher requires all students to practice again; for personal mistakes, the system will automatically push different exercises, and the teacher will send different exercises according to the students' cognitive level. In principle, the high-level students will be provided with difficult exercises, the lower-level students will get the most basic exercise problems, and the middle-level students will be provided with middle-level difficult exercises.

\section{Establish Strict Online Learning and Teaching Management System}

\section{Requirements for Online Teaching}

There are several unifications in online teaching: unified data, unified progress, unified training, and class time. The team leader prepares an emergency team in advance. According to the progress of the second round of review, allocate resources and integrate tasks with monthly and weekly plans. The teaching and training materials, electronic documents, PowerPoint, and micro-learning vary from day to day in the unified grade online course. The grade leader arranges the class schedule for the whole year, unifies the time of each subject, and unifies the students' pace.

\section{Strict Management of Online Teaching}


- Time Management: The school develops class schedules for third-year online learning, and conducts student and teacher attendance checks in strict accordance with the schedules.

Before 8:00 am, the head teacher posted a health check-in task through the public office communication platform "Dingding" to carry out student attendance; administrative management (leaders above the middle level) stationed in the "Dingding" group of each class to watch the live broadcast and conduct attendance of the subject teacher.

From 8:00 am to 10:40 am, students conduct autonomous learning based on the learning tasks (simulated sets of papers or time-limited trainings, Chinese and English famous words or word recitations) released by teachers of various subjects in the "Dingding" class group, and are required to submit assignments according to the prescribed time.

From 10:40 am to $12: 00 \mathrm{pm}$, Chinese or mathematics teachers will conduct homework reviews or special lectures through "Dingding" live broadcast according to the progress of the second round of review and the students' homework.

From 14:30 pm to 17:40 pm in the afternoon, teachers of English, Liberal Arts or Liberal Arts courses will be arranged for live teaching. The online teaching time for each subject is one hour.

- Behavior Management: Teachers and administrators manage online teaching activities through the "Dingding" platform

Teachers use the Dingding platform to publish homework at the prescribed time (before 8:00 am) through the home-school interactive platform. According to the submission of the homework, they understand the completion of the homework and submit comments. Provide timely reminders to students who have not completed in time, and if necessary, contact the students' parents to learn about the situation.

Administrative personnel need to know well the layout and correction of teacher assignments based on the teacher's home-school interaction platform and the operations in the corresponding class sections. The Teaching Office conducts brief reports on teachers' teaching activities every week.

- Emotional Management: During the epidemic prevention and control stage, teachers, students, and even parents, especially the senior high school students, may have bad emotional changes such as extreme anxiety. The school uses large and small classes to carry out epidemic prevention and control, and provides campus with hotlines of psychological counseling to help teachers, students, and parents' mental health management.

\section{The Effectiveness of Using Online Platforms to Im- plement Teaching during the COVID-19 Epidemic}


During the epidemic, students learn autonomously by watching videos of famous school classrooms and school micro-classes provided by the Provincial Department of Education. On the basis of students' self-directed learning, the teacher answers questions through live broadcasts online, and guides students' problems in the learning process in a timely manner, thus gradually formed a student-centered online teaching model. At the same time, the educational big data system is used to collect, statistically analyze and accurately deliver student learning data.

On the one hand, it helps teachers master the students' process learning data to effectively improve teaching. On the other hand, it frees students from the traditional problem-solving tactics, and provides personalized and accurate practice materials to help students improve the efficiency of practice and achieve the maximum practice effect in a limited practice time. Teaching and learning promote each other. This really helps the school to improve the quality of teaching, and help students improve their performance, and then achieve personalized learning for students, targeted teaching for teachers.

It is undeniable that in the process of practice, students' ability to learn independently has been tested tremendously. At the same time, teachers need time to prepare lessons online, correct and live teaching. Teachers' online teaching work is overloaded. How to ensure the needs of students and teachers on the premise of ensuring the quality of online teaching is an urgent problem to be solved in the online teaching model.

\section{References}

Erik, W.B., Richard, E.F., Meredith, D. (2008) An overview of evaluative instrumentation for virtual high schools. Am J Dist Edu, 22(1):24-45.

Garrison, D.R., Terry, A. (1998) E-learning in the 21 century. Rout ledge Falmer.

$\mathrm{Ke}, \mathrm{Q}$. (2013). Big data and smart education .Chin Educ Inform, 24: 8-11.

Lv, L., Shao, Y., Sun, H., Feng, C., Zhuang, S., et al. (2017) 2016-2017 Blue Book of Chinese Internet Education Industry. Bei- jing: Peking University Press, O5-O1: pp156.

Wang, Q. (2020) How to carry out online learning efficiently. China Education Daily, 02-26-2020.

Yang, X., Tang, S., Li, J. (2016) Developing big data for education: connotation, value and challenges.Res Modern Dist Edu, (01):50-61.

Zhang, Z., Tong, J. (2010) Research on cloud computing-based educational information platform. Chin Dist Edu, (6):66-69. 
Zhao et al. Teaching Strategies with Education Platform during the COVID-19 Epidemic.

Received: 02 March 2020

Revised: 11 March 2020

Accepted: 26 March 2020 